Article

\title{
Identifying Irrigation Strategies for Improved Agricultural Water Productivity in Irrigated Maize Production through Crop Simulation Modelling
}

\author{
Geneille E. Greaves ${ }^{1}$ and Yu-Min Wang ${ }^{2, *}$ \\ 1 Department of Tropical Agriculture and International Cooperation, National Pingtung University of Science \\ and Technology, 1 Shuefu Rd., Pingtung 912, Taiwan; geneilleg@gmail.com \\ 2 Department of Civil Engineering, National Pingtung University of Science and Technology, 1 Shuefu Rd., \\ Pingtung 912, Taiwan \\ * Correspondence: wangym@mail.npust.edu.tw; Tel.: +886-8-770-3202 (ext. 7181)
}

Academic Editor: Marc A. Rosen

Received: 9 February 2017; Accepted: 13 April 2017; Published: 17 April 2017

\begin{abstract}
Identifying irrigation strategies that improve agricultural water use efficiency (WUE) have a pivotal role to play in sustainable water development. In this study, the AquaCrop model was used to examine the impact of different irrigation scheduling options on yields to identify viable strategies to enhance WUE for irrigated maize. Two scheduling scenarios at water application depths ranging from 20 to $50 \mathrm{~mm}$ were investigated: schedules based on allowable depletion of total available water (TAW) in the root zone and interval schedules based on irrigating at predefined daily intervals. For both scenarios, simulated yields, seasonal water applied and percent percolation loss were within the range of 9.16 to 10.22 ton/ha, 180 to $950 \mathrm{~mm}$ and $0-61 \%$, respectively. The WUE in terms of water applied $\left(\mathrm{WUE}_{\mathrm{Irr}}\right.$ ) and crop evapotranspiration (WUE $\mathrm{ET}_{\text {) }}$ ranged from 1.07 to $5.48 \mathrm{~kg} / \mathrm{m}^{3}$ and 2.42 to $4.42 \mathrm{~kg} / \mathrm{m}^{3}$, respectively. The results revealed that depletion levels of $40-50 \%$ TAW at water depths of 20-40 mm could be used to obtain high WUE without significant yield penalty. Moreover, a good balance between yield, improved WUE $\mathrm{ET}_{\mathrm{T}}$ and percolation reduction was observed at water depths of 30-40 $\mathrm{mm}$ for daily intervals with water applied during the vegetative-reproductive stage of 7-5, 10-5 and 10-7. The identified strategies can contribute to the development of best management practices for water conservation.
\end{abstract}

Keywords: water use efficiency; AquaCrop; irrigation schedules; maize; water conservation

\section{Introduction}

Irrigation is a major driver in ensuring food security and essential ecosystem functions. It is vital for sustainable management and protection of soil resources, improving groundwater storage, enhancing the use of agriculture inputs, such as fertilizers, facilitating continuous cropping and improving agricultural production [1]. However, as global population continues to expand rapidly and the implications of climate change are omnipresent, irrigated agriculture, which is at least two-times more productive than rain-fed agriculture, is placed under immense pressure to increase food production and to release water for other high-value uses. Globally, irrigated agriculture is the largest consumer of available fresh water resources, but it is projected that the water that will be available for irrigation will decrease as water is diverted towards non-agricultural sectors [2]. Against these backdrops and in the context of dwindling fresh water reserves, it is imperative that the agricultural sector use its irrigation water more efficiently.

Exploring and identifying strategies to achieve a substantially more efficient and productive use of water in irrigation can be done through field experimentation and or crop growth simulation 
models. Field experiments are however limited by the time and cost ineffectiveness to examine the non-exhaustive list of potential irrigation scenarios. Cropping models that reliably simulate a crop growing environment and its effect on crop production offer a viable alternative to field experiments, as they allow a conjunctive assessment of various environment and management factors [3]. Further, when combined with frequency analysis and historic climatic input data, cropping models can effectively identify optimal management strategies, in terms of both timing and dose irrigation application, under varying weather conditions [3,4]. In this context, models provide valuable information about the trade-offs among different scenarios, in terms of crop productivity against improved water use efficiency (WUE), thus providing decision support for selecting irrigation projects, and contribute to the minimization of subjectivity in policy or project decisions.

The capability of models to adequately simulate crop growth and development under different management practices is one of the challenges to modern agricultural production, and over the last century, the number of crop simulation models has increased. These models differ in their scales of application, complexity, input variables and crop "growth engines". The recently developed AquaCrop model $[5,6]$ is a water-driven growth engine model that maintains an optimal balance between accuracy and robustness [7]. Owing to a relatively small number of input parameters AquaCrop is relatively simple compared to other crop models, and the literature account demonstrates that this feature has not limited its performance to accurately simulate crop growth and productivity. Abi Saab et al. [8] showed that AquaCrop performance in simulating barley growth under different irrigation regimes was equal to, and even superior to in some cases, the Cropping Systems Simulation model (CropSyst). In comparing AquaCrop to the crop models CropSyst and WOFOST (World Food Studies) for simulating sunflower biomass and yield under different water regimes, Todorovic et al. [9] concluded that AquaCrop predictions are comparable to the results of these two models. Amiri et al. [10] showed that AquaCrop estimated biological yield of rice more accurately compared to the models CERES-Rice (Crop Environment Resource Synthesis-Rice) and ORYZA2000.

According to Levidow et al. [11], greater WUE in agriculture should not be constrained to expectations of irrigation technology, but emphasis should also be placed on optimizing agricultural practices as they provide other complementary benefits such as reduced energy needs. In this context, irrigation scheduling is a viable practice that can facilitate the improvement of WUE in irrigated agriculture. Igbadun et al. [12] highlights that effective irrigation scheduling can lead to significant water savings, preservation of environmental integrity and improved sustainability of irrigated agriculture. Irrigation scheduling is the technique accurately and in a timely manner give water to the crop. Traditionally, crop production focused primarily on maximizing yields. However, in recent years, focus has shifted to the limiting factors in agricultural production systems, such as water, and agricultural water productivity is now an integral part of the decision making process. Further, it is perceived that irrigated agriculture will need to adopt a new management paradigm based on the maximization of net benefits and plan for some degree of crop water stress [13]. Identifying irrigation strategies for improving agricultural water productivity and or determining protocols for water shortages requires rigorous exploration of the different water management options. Crop simulation models are ideally suited to examine the effectiveness of the numerous alternatives.

The effect of irrigation regimes on crop yield and WUE varies with crops and is acknowledged to be location and climate specific [14], highlighting the need to investigate the suitability of different scenarios in localized environments rather than extrapolating results from other regions. The objective of this study was to identify potential strategies for improving WUE in maize production in southern Taiwan through the use of simulation modelling. The study investigated two different irrigation-scheduling scenarios. The results should provide insights about irrigation water requirements during the cropping season under variable climate scenarios and guidelines for each irrigation scheduling scenario for optimal water management to farmers. 


\section{Materials and Methods}

\subsection{Study Location}

The study area under consideration is the rural agricultural township of Neipu in Pingtung County, southern Taiwan. The location experiences a tropical wet and dry climate with an extreme spatial and temporal distribution of rainfall; more than $80 \%$ of the annual precipitation occurs during the summer months from May to October and is generally concentrated in several storms and typhoon events [15]. Thus, the main cropping period typically extending from November is generally characterized by a lack of rainfall often demanding supplemental water application. In fact, Sakthivadivel et al. [16] highlights that the precipitation is extremely unevenly distributed in space and time necessitating irrigation for agricultural production. Furthermore, Liou et al. [17] observe that although the average annual rainfall is about three-times higher than the world average, only a small portion is stored over the land and accessible for use given the steep mountainous terrain, resulting in most of the precipitation flowing directly into the sea. In this regard, the maximization of water resources is imperative, and emphasis must be placed on making efficient use of agricultural water.

\subsection{The Crop Simulation Model Used}

The crop simulation model used for this study was the AquaCrop (v. 5.0) (FAO-Land and Water Division, Rome, Italy) water productivity model [5]. Data acquired from field experiments across three seasons were used to calibrate and validate the model for simulating maize production in southern Taiwan for loamy soils [18]. These experiments were conducted at the irrigation experimental site of National Pingtung University of Science and Technology $\left(22.65^{\circ} \mathrm{N}, 34.95^{\circ} \mathrm{E}: 71 \mathrm{~m}\right.$ above sea level). During the field experiments, level basin surface irrigation was employed, as this is the common irrigation method used in the study location for maize. Thus, during the calibration and validation process, this irrigation management option was selected in AquaCrop, and in this study, simulations were performed under this irrigation management option.

The AquaCrop model provides a sound theoretical framework to investigate crop yield response to environmental stress [7]. The model converts daily transpiration directly to daily biomass production using daily reference evapotranspiration $\left(\mathrm{ET}_{\mathrm{o}}\right)$ and normalized water productivity and simulates crop yield as the product of daily biomass and the harvest index (HI) [5]. As water is the driving force for growth within the model, AquaCrop also simulates the change of water stored in the soil throughout the growing season by means of a soil water balance. That is, the model tracks all incoming (rainfall, irrigation and capillary rise) and outgoing (runoff, evapotranspiration and deep percolation) water fluxes at the boundaries of the root zone; thus, the amount of water retained and depleted in the root zone can be calculated at any moment of the season [19]. This makes it an effective tool for investigating different irrigation scheduling options and its effect on crop productivity. AquaCrop has several options available for irrigation "timing" criteria and water "depth" criteria from which the user can select.

The input data required in the model include weather, soil, crop and management data and irrigation scheduling decisions. The weather data required are daily maximum and minimum ambient temperatures, daily precipitation and daily reference evapotranspiration $\left(\mathrm{ET}_{\mathrm{o}}\right)$ for the entire cropping cycle. Raes et al. [5,19] and Steduto et al. [6] outline in detail all input data required by the model to perform simulations and discuss at length the structure, principles and algorithms of the model. Greaves and Wang [18] present details about data input for calibrating the model for the study location.

\subsection{Simulation Procedure}

Developing guidelines for improving agricultural water use in irrigated maize production is inherently dependent on crop water requirement and quality of the precipitation during the cropping season. Additionally, local management practices and constraints and limitations to the farmer should 
be taken into consideration in the decision making process. The simulation procedure for identifying irrigation strategies to enhance maize WUE consisted of three main steps.

First, historic weather data were statistically analyzed to obtain indicative degrees of water availability that can be expected during the cropping period. Similar to the methodology employed in other studies $[3,20,21]$, three different classes of seasons were established: seasons of average (normal) water demand (50\% probability exceedance (PE)), low demand or wet season (20\% PE) and high demand or dry season ( $80 \%$ PE). Liu et al. [22] postulates that these characteristic seasons can effectively aid in representing varying climate scenarios and demand conditions for irrigation. To classify these characteristic seasons, frequency analysis of available historic rainfall depths (2000-2015) was analyzed with RAINBOW [23], and the typical rainfall received in the dry, normal and wet seasons was identified. In RAINBOW, there are several probability distribution options available for fitting the data. In this study, the normal distribution was utilized, and the data were transformed using the logarithm function to optimize the fit. Kolmogorov-Smirnov statistical tests indicated that this distribution was a good fit. Dependable levels of rainfall estimated from frequency analysis of historic data projects $31 \mathrm{~mm}$ in a dry season $(80 \% \mathrm{PE}), 58 \mathrm{~mm}$ in a normal season $(50 \% \mathrm{PE})$ and $97 \mathrm{~mm}$ for a wet season $(20 \%$ PE). Following the works of Geerts et al. [3], three characteristic years with precipitation levels similar to the precipitation with $20 \%, 50 \%$ and $80 \%$ PE were then selected for the simulation study in AquaCrop. Interpretation of the characteristic dry, normal or wet season can be based on expert knowledge from the farmer or forecasted weather.

After identifying the three characteristic years, the model was then prepared for the simulation study. The weather data for these years were used to create independent climate files, and $\mathrm{ET}_{\mathrm{o}}$ was estimated using the FAO Penman-Monteith equation [24]. The estimated $\mathrm{ET}_{\mathrm{o}}$ for the years representing the dry, normal and wet characteristics season was 493, 507 and 489, respectively. The soil data obtained from the research fields and the crop data used to calibrate the model [18] were input into the model to be used in the simulation process. By considering local practices and crop characteristics, the following assumptions were made: sowing was done on 20 November; the length of the cropping cycle was 120 days; and the initial soil water content (SWC) in the root zone was fixed at $100 \%$ of the total available water (TAW) in the root zone. This latter assumption arises from the fact that the typhoon season concludes in October and/or pre-sowing irrigation can be used to increase the SWC when off-season rainfall is low.

In Step 3, simulations were run for the complete growing cycle for the three selected years. Two scenarios for irrigation scheduling were considered. For both scenarios, water application depths of $20 \mathrm{~mm}$ (D1), $30 \mathrm{~mm}$ (D2), $40 \mathrm{~mm}$ (D3) and $50 \mathrm{~mm}$ (D4) were considered. In the first scenario, irrigation was based on management allowable depletion (MAD), in which irrigation will be initiated at a predefined percent depletion of total available water (TAW) in the root zone. Four depletion levels of the TAW in the root zone were considered in the analysis: 30\% (T1), 40\% (T2), 50\% (T3) and 60\% (T4); and for each depletion level, each water depth was tested. The various depletion (T) by depth (D) combinations ( $\mathrm{TnDn}$; where $\mathrm{n}$ is the above-mentioned numbers representing the different depths or depletion levels) resulted in 16 simulation runs per characteristic year. The second scenario considered an interval schedule in which irrigation water application would occur at predefined daily intervals. Again, each water depth was simulated for each interval considered. This method would be valuable at the farm level where equipment needed to monitor the depletion levels is not readily available. Six irrigation-scheduling intervals were simulated: 3 fixed intervals of every 5 days (Int5), 7 days (Int7), and 10 days (Int10); and 3 variable intervals where the intervals were switch to shorter times during the critical reproduction growth stage resulting in Int7-5, Int10-5 and Int10-7 (the first and second numbers indicate the daily interval during the vegetative and reproductive stage, respectively). Here, based on observations from field experiments, it was assumed that the reproductive stage will begin from 65 days after planting (DAP). Further, for both scenarios, it was assumed that irrigation water management would commence from maize six leaf (V6) growth stage; thus, no irrigation water application would be applied until 25 DAP. The interval (Int) by depth (D) combination (IntnDn; where $\mathrm{n}$ is 
the above-mentioned numbers representing the different depths or intervals) resulted in 24 simulations run for the three characteristic seasons. Thus, a total of 120 simulations ( 4 depths $\times 4$ depletion schedules $\times 3$ years +4 depths $\times 6$ interval schedules $\times 3$ years) were analyzed in this study.

The final step comprised analyzing the output variables. Those considered were grain yield, seasonal water applied, evapotranspiration (ET), deep percolation and crop water productivity. Two-way analysis of variance (ANOVA) tests were carried out for each of the output variables to study the effect of the water application depths and the scheduling practices on the output variables. Additionally, where applicable, Tukey's significant test was used to separate the means for the two factors.

\section{Results and Discussion}

\subsection{Soil Water Dynamics and Irrigation}

Figure 1 illustrates the simulated seasonal variation of soil water content in the 1-m soil profile depth for the normal characteristic season for selected strategies. In general, as the depletion levels increased, the frequency of water application decreased, since the irrigation was triggered later (Figure 1a,b). Additionally, it can be observed (Figure 1c,d) that the lower the application depth (for the same depletion level), the greater the frequency of water application. These observations have important implications, as crop productivity depends not only on the timing and severity of water deficits, but is also influenced by the duration of the drying cycle between water application $[7,14,25]$. Comparison between the presented strategies shows that in general, soil moisture deficits were also more pronounced at high depletion levels (Figure 1a), especially at a low water depth (Figure 1d). Similar observations were made for the dry and wet characteristic seasons, as this irrigation scheduling approach was based on the percent depletion of water in the root zone.
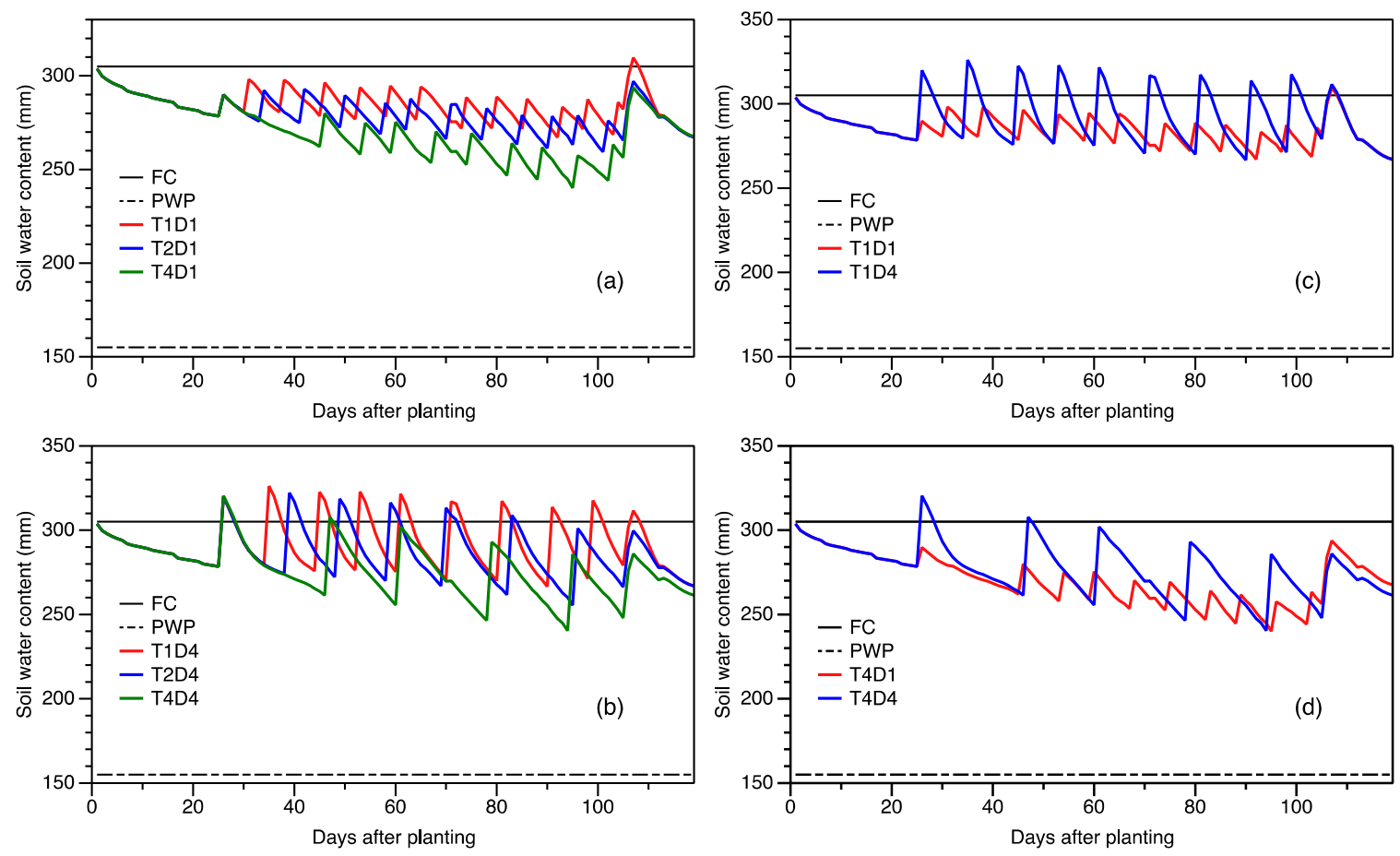

Figure 1. Variation in soil moisture content for the normal characteristic season for the selected strategies. Note: FC is the field capacity; PWP is the permanent wilting point; T1, T2, and T4 is the depletion levels of $30 \%, 40 \%$ and $60 \%$, respectively; and D1 and D4 is the water depths of $20 \mathrm{~mm}$ and $50 \mathrm{~mm}$, respectively. 
Simulated seasonal water applied for the various depletion levels at varying water application depths is depicted in Figure 2a-c for the three characteristic seasons. The results presented show that for a dry season, the seasonal water applied varied from 260 to $500 \mathrm{~mm}, 260$ to $400 \mathrm{~mm}, 260$ to $300 \mathrm{~mm}$ and 220 to $300 \mathrm{~mm}$ for depletions levels 30\% (T1), 40\% (T2), 50\% (T3) and 60\% (T4), respectively, depending on water application depth. Similarly, for a characteristic normal season, the respective ranges for these depletion levels were $260-450 \mathrm{~mm}, 260-350 \mathrm{~mm}, 240-300 \mathrm{~mm}$ and $240-250 \mathrm{~mm}$. The quantities simulated for the characteristic wet season were smaller with T1, T2, T3 and T4 having ranges of $240-450 \mathrm{~mm}, 240-300 \mathrm{~mm}, 220-300 \mathrm{~mm}$ and $200-250 \mathrm{~mm}$, respectively. The ANOVA test indicated highly significant differences $(p<0.01)$ in seasonal water applied among the five schedules, which can be attributed to the frequencies of irrigation. In general, a typical range of crop water requirement for maize crop is about 500-800 $\mathrm{mm}$ [14]. The simulated irrigation water supplied under the interval irrigation management is depicted in Figure 2d. As this management is based on water application at predefined intervals, the same amount of water was supplied for all characteristic seasons. The simulated water applied varied from a low of $180 \mathrm{~mm}$ in Int10D1 to a high of $950 \mathrm{~mm}$ in Int5D4. The variable interval schedules (Int7-5, Int10-5 and Int10-7) where the intervals between irrigation applications during the reproductive growth stage were reduced recorded higher water application amounts than their fixed counterparts (Int7, Int10).
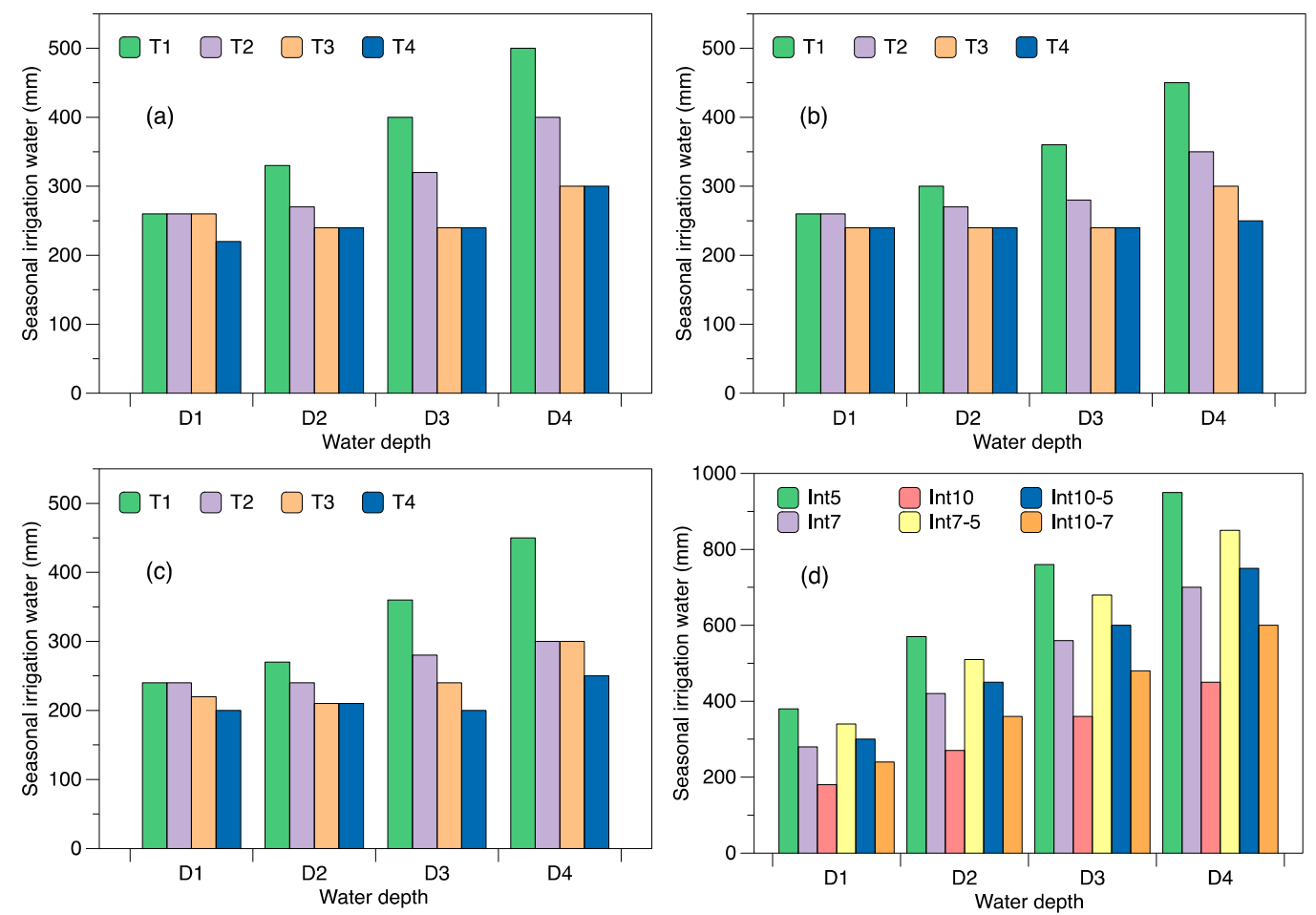

Figure 2. Simulated seasonal water applied for the (a) dry, (b) normal and (c) wet characteristic seasons for the depletion scheduling method and (d) for the various interval schedules. Int5, interval of five days.

Deep percolation loss was considerably higher for the interval scheduling method than the depletion method. For the depletion scheduling method, losses were observed for only a few combinations generally occurring for the larger water depths. The most significant losses observed for the dry and normal season were $9 \%, 22 \%$ and $11 \%$ and $11 \%, 22 \%$ and $12 \%$, respectively, for the respective strategies T1D3, T1D4 and T2D4, and for the wet season, slightly higher amounts of $11 \%$, $24 \%, 8 \%$ and $13 \%$ were simulated for T1D3, T1D4, T2D3 and T2D4, respectively. These values are presented as a percentage of the total water applied (irrigation + rainfall). The deep percolations simulated in AquaCrop for the various interval schedules at various water application depths are 
depicted in Figure 3. As can be observed, losses increased with an increase in water application depth per irrigation, and values were higher in the characteristic wet season. Across the three characteristic seasons, the deep percolation losses for Int5, Int7, Int10, Int7-5, Int10-5 and Int10-7 varied between $11 \%$ and $61 \%, 0 \%$ and $49 \%, 0 \%$ and $28 \%, 0 \%$ and $57 \%, 0 \%$ and $51 \%$ and $0 \%$ and $41 \%$ of the total water applied, respectively. In terms of water application depths, an application of 40 and $50 \mathrm{~mm}$ often resulted in high loss of water to deep percolation; five out of the 36 cases resulted in losses less than $21 \%$; and most (four) of these cases occurred for the schedule Int10. Considering the daily intervals, across the three characteristic seasons, the more frequent five-day schedule (Int5) continually recorded the greatest percolation losses for any water depth (Figure 3) with nine out of the 12 cases resulting in losses greater than $36 \%$. Overall, the 10-day schedule (Int10) followed by the 10-day-7-day schedule (Int10-7) produced the lowest losses and greater number of $0 \%$ loss. High deep percolation loss (up to $1133 \mathrm{~mm}$ ) at short irrigation intervals and high water application have been reported in other simulation studies evaluating interval scheduling $[12,14]$. Besides the obvious negative impact on the efficiency of agricultural water use, Igbadun and Salim [14] highlight that some of the consequences of high percolation losses include rapid build-up of the water table, the increase in soil salinity and water logging, which leads to poor yield due to low soil temperatures and poor aeration of plant roots.
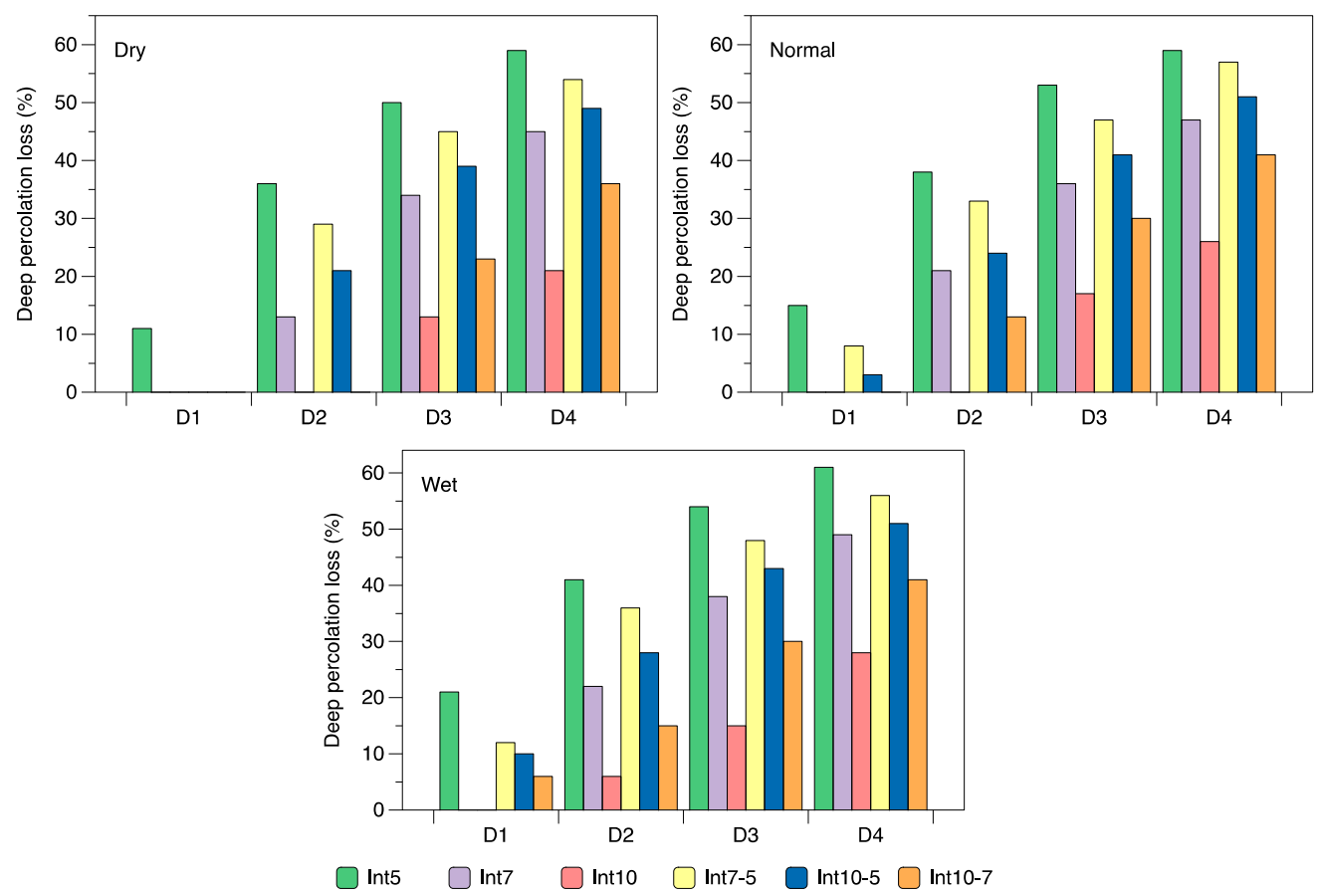

Figure 3. Simulated deep percolation loss as a percent of total water applied for the three characteristic seasons for the interval scheduling method at various water application depths.

\subsection{Simulated Crop Evapotranspiration}

Figure 4 shows the simulated seasonal evapotranspiration (ET) for the different water application depths for the depletion irrigation scheduling. Across the three characteristic seasons, seasonal ET for the different schedules ranged from 305 to $415 \mathrm{~mm}$ for T1, 295 to $393 \mathrm{~mm}$ for T2, 275 to $361 \mathrm{~mm}$ for $\mathrm{T} 3$ and 275 to $341 \mathrm{~mm}$ for T4. These simulated values fall within the range of seasonal consumptive water use reported in other simulation studies for maize [12,14] and some deficit studies observed through field experimentation [26]. However, the lower values appear to be outside (below) the range of other field studies $[27,28]$. Higher ET values were observed for lower depletion schedules and larger water application depths, indicating that these treatments were less susceptible to water deficits. The variation in simulated ET for the interval schedules and water application depths across all characteristic seasons is depicted in Figure 5. For the three characteristic seasons, the lowest ET 
values were observed for the Int10 schedule ranging from 230 to $391 \mathrm{~mm}$ followed by the Int10-7 schedule with a range of 275 to $411 \mathrm{~mm}$. The simulated ET for the four remaining schedules was within the range of 315 to $411 \mathrm{~mm}$. The two-way ANOVA results indicated that overall, the variation in simulated ET was highly significant at the $1 \%$ level for all characteristic seasons for the various depletion (Tn) and interval schedules (Intn), while the mean ET associated with the water application depths (Dn) were significantly different at $5 \%$. However, similar to the results reported by Igbadun and Salim [14], no significant interaction effects were observed in either irrigation scheduling scenario, implying that the variation was not a result of the combined effect of the depletion levels and water application depth or interval schedules and water application depth. Further analysis revealed that the mean ET was significantly different among some groups (Tables S1 and S2). In particular, highly significant differences were observed for T1 scheduling compared to the other Tn schedules (Table S1). Additionally, in terms of water depths, the only significant difference observed was for D4 compared to the water depths D1 and D2. With regards to the different scheduling intervals, the mean ET for Int10 was significantly different from Int5, Int7, Int7-5 and Int10-5 across the dry and normal characteristic seasons, while for the wet season, Int10 was significantly different only for Int5, Int7 and Int7-5 (Table S2). For the other schedules, Tukey's test statistic indicated that there was no significant difference. As regards the water depths, significant differences were observed for D1 compared to all other water depths across all three characteristic seasons (Table S2).
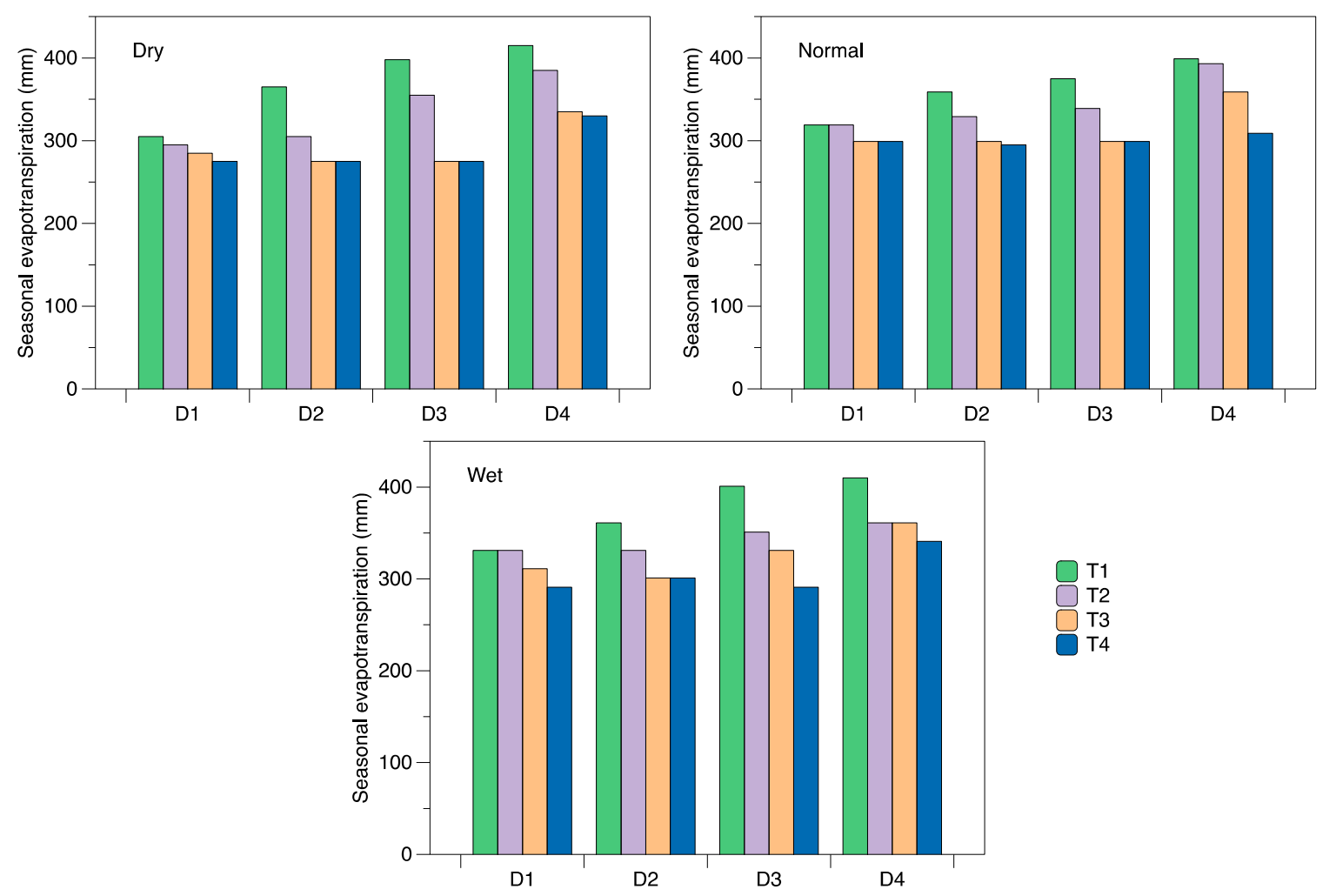

Figure 4. Simulated seasonal evapotranspiration for the four depletion schedules at varying water depths for the dry, normal and wet characteristic seasons. 

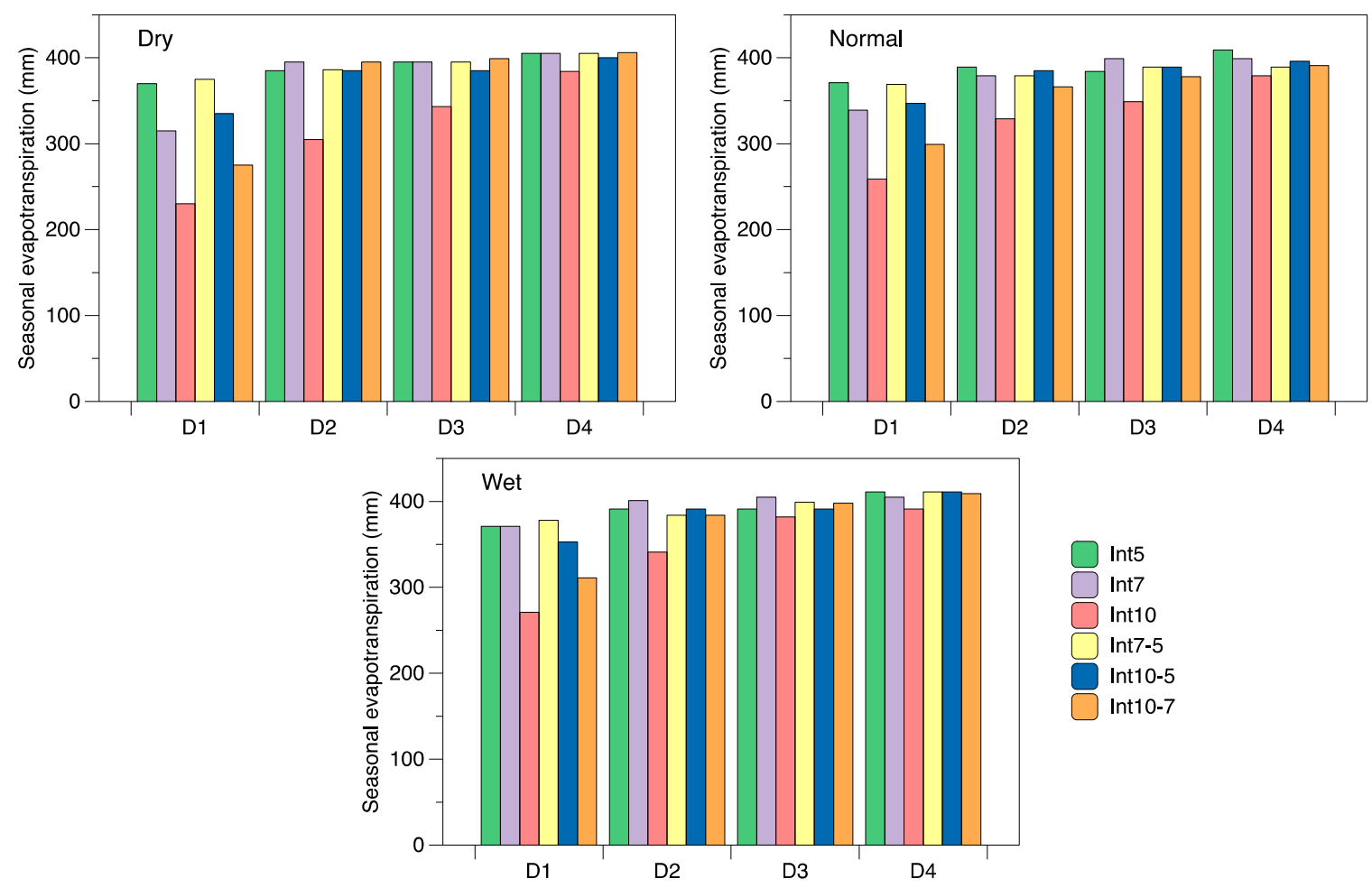

Figure 5. Simulated seasonal evapotranspiration for interval schedules at varying water depths for the dry, normal and wet characteristic seasons.

\subsection{Simulated Grain Yield}

Simulated yields for the different depletion levels and water application depths for the three characteristic seasons of water availability are presented in Figure 6. In a dry, normal and wet season, the simulated yields ranged from 9.16 to 10.05 ton/ha, 9.41 to 10.09 ton/ha and 9.51 to 10.22 ton/ha, respectively. The yields obtained in this simulation study are within the range reported for the study area based on field experiments [18]. Irrigation based on the lower depletion levels typically produced higher yields than the higher depletion levels (Figure 6). In general, the highest yields were obtained when irrigation water application depth was at least $40 \mathrm{~mm}$ for schedules T1 and T2. Further, as can be observed from the figure, in most cases, there is no considerable difference between the yields obtained for T1 and T2 scheduling, indicating that the increase in irrigation application did not result in an appreciable increase in productivity, presenting opportunities for water savings. Simulated water application for T1 was considerably higher at these water depths (Figure 2). Deep percolation losses for some of these treatments further suggest that the crop was over-irrigated. In addition, for the wet characteristic season, there was also no substantial reduction in the simulated yield of T3D3 and T3D4 compared to the maximum yields observed in $\mathrm{T} 1$ and $\mathrm{T} 2$, indicating that utilizing a water depth of $40-50 \mathrm{~mm}$ at a $50 \%$ depletion of TAW in the root zone is a viable strategy to consider for this climate scenario. Here, a reduction of $2.5 \%$ and $1.29 \%$ for these two strategies was observed respectively. In the study, AquaCrop simulation output for biomass ranged from 19.96 to 20.73 ton/ha, 20.16 to 20.64 ton/ha and 20.43 to 20.57 ton/ha for the dry, normal and wet characteristic seasons. The impact of the different irrigation strategies on crop growth under the depletion irrigation scheduling method is illustrated in Figure 7 for selected strategies. The ANOVA test indicated that overall, there was a significant difference $(p<0.05)$ among the mean grain yield for the different depletion schedules and for the varying water application depths for all characteristic years. Further analyses revealed that generally, the mean grain yields were not significantly different when the water application was above $30 \mathrm{~mm}$ (D2) (Table S1). Contrastingly, the difference in simulated yields was significant among most of the schedules, especially for the wet season. 

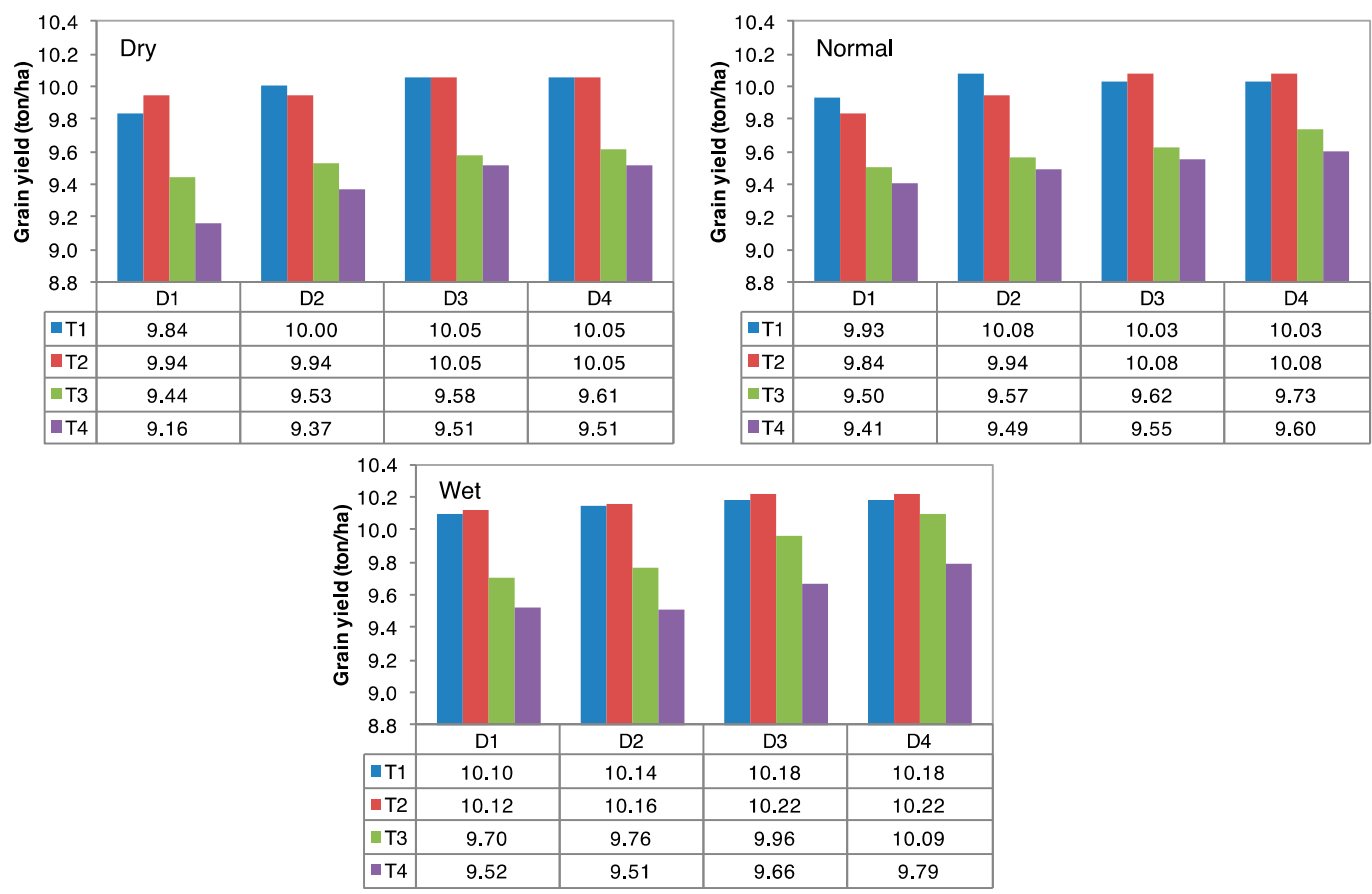

Figure 6. Simulated grain yield for the different depletion schedules for the three characteristic seasons. Note: T1, T2, T3 and T4 represent depletion levels of 30\%, 40\%, 50\% and 60\%, respectively; D1, D2, D3 and D4 represent water depths of $20 \mathrm{~mm}, 30 \mathrm{~mm}, 40 \mathrm{~mm}$ and $50 \mathrm{~mm}$, respectively.
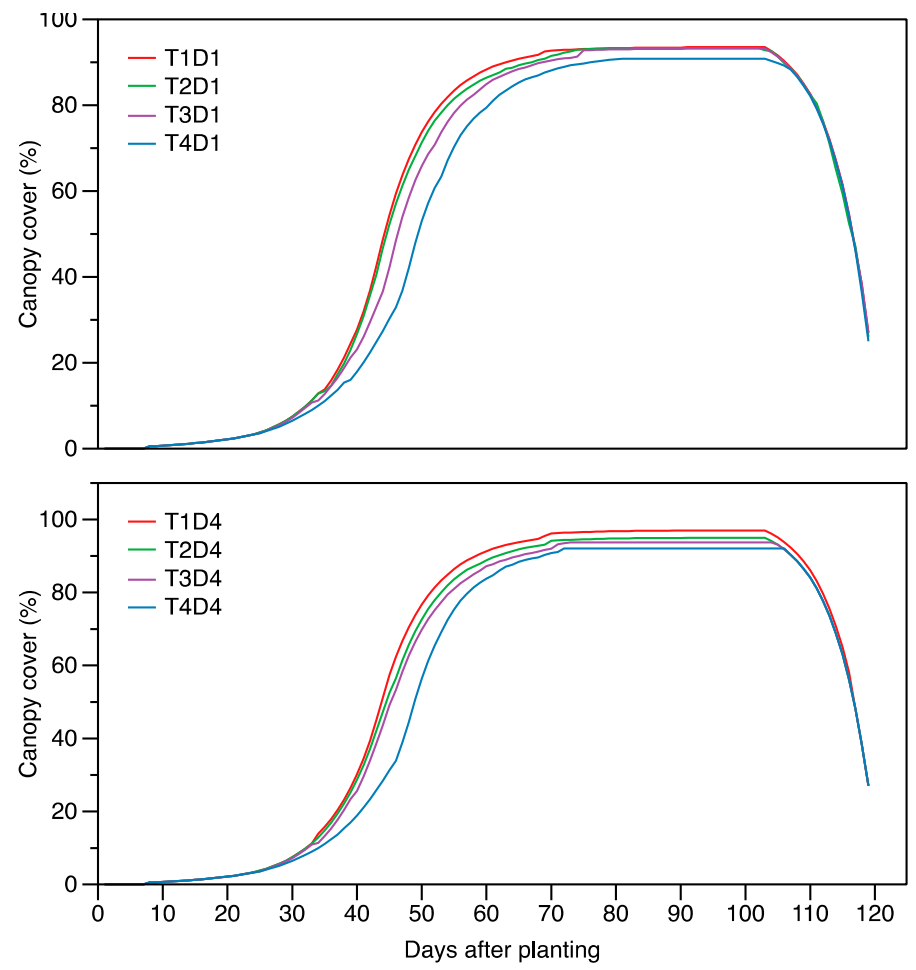

Figure 7. Simulated canopy cover for selected strategies for the normal characteristic season. Note: T1D1, T2D1, T3D1 and T4D1 represent depletion levels of 30\%, 40\%, 50\% and $60 \%$ at a water application depth of $20 \mathrm{~mm}$, respectively; T1D4, T2D4, T3D4 and T4D4 represent these respective depletion levels at a water application depth of $50 \mathrm{~mm}$. 
Figure 8 presents the yield simulated in AquaCrop for the different interval schedules at various water application depths. Across the three characteristic seasons, the yield for the schedules Int5, Int7, Int10, Int7-5, Int10-5 and Int10-7 were within the range of 10.10 to 10.18 ton/ha, 9.85 to 10.02 ton/ha, 9.40 to 9.92 ton/ha, 9.94 to 10.07 ton/ha, 9.57 to 9.95 ton/ha and 9.54 to 9.95 ton/ha. Higher yields were generally observed in the wet characteristic season. The relative reduction in yield for the dry, normal and wet characteristic season, estimated from the maximum simulated yield in each season, varied from $0.62 \%$ to $6.52 \%, 0.22 \%$ to $7.1 \%$ and $0.48 \%$ to $3.18 \%$, respectively. The lowest yields and thus highest percent reduction were observed in the Int10 schedule, whilst the maximum yield was observed in the Int5 schedule. Two-way ANOVA testing revealed that overall, there was a significant difference in mean yield for the different interval schedules and for the varying water application depths for all characteristic seasons. The result of Tukey's significance test revealing groups in which the yields were significantly different is presented in Table S2. As with the simulated ET, a significant difference was observed for D1 compared to all other water depths across the three characteristic seasons. Considering the interval schedules as the factor, the higher yields simulated in the Int5 schedule were significantly different from the yields simulated in most of the other schedules (Table S2). For the remaining comparisons, significant differences for the mean yields for the dry and normal seasons were observed between only a few of the other interval schedules. In contrast, for the wet season, the mean yield was significantly different across the remaining comparisons, except Int10-5 vs. Int10-7.
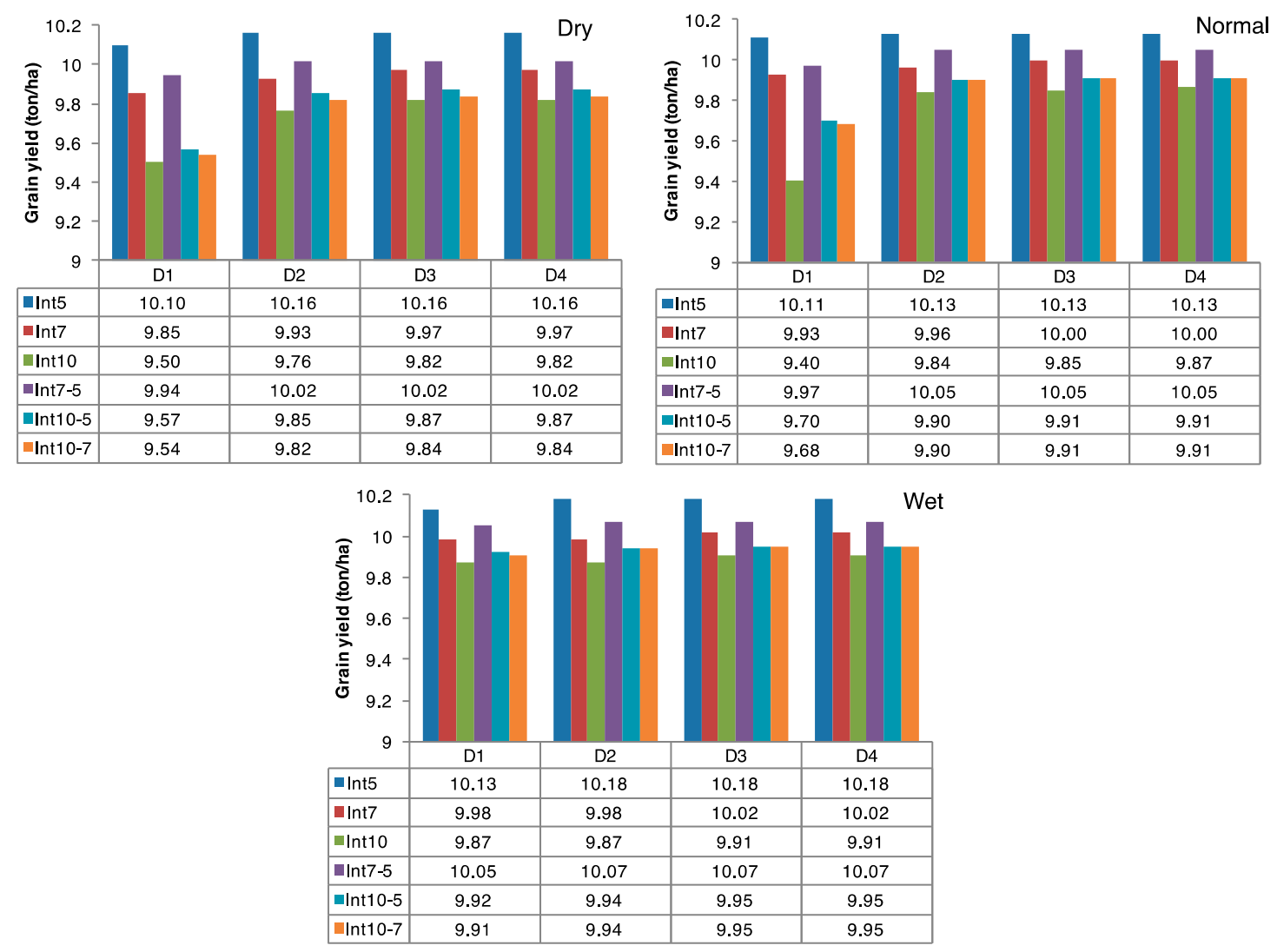

Figure 8. Simulated grain yield for the different interval schedules at various water depths for the three characteristic seasons. Note: D1, D2, D3, D4 refer to water depths of $20 \mathrm{~mm}, 30 \mathrm{~mm}, 40 \mathrm{~mm}$ and $50 \mathrm{~mm}$, respectively.

\subsection{Crop Water Productivity}

Table 1 shows the simulated crop water productivities for the different irrigation strategies under the depletion scheduling method in terms of seasonal water applied $\left(\mathrm{WUE}_{\mathrm{Irr}}\right)$ and crop consumptive 
use $\left(\mathrm{WUE}_{\mathrm{ET}}\right)$, estimated as yield per unit total irrigation water supplied and $\mathrm{ET}_{\mathrm{c}}$, respectively. In general, the WUE $\mathrm{Err}_{\text {Ir }}$ was higher during the wet season, as less water was supplied to meet crop water requirements, and increased as the depletion criterions increased, since water application was less frequent. Furthermore, estimated values in the table show that in most cases, there was no considerable difference between the values for the depletion schedules T3 and T4 for the dry and normal characteristic seasons. During the characteristic dry season, WUE $E_{\text {Irr }}$ ranged from $2.01 \mathrm{~kg} / \mathrm{m}^{3}$ in T1D4 to $3.99 \mathrm{~kg} / \mathrm{m}^{3}$ in T3D2 and T3D3; for the characteristic normal season, the values ranged from $2.23 \mathrm{~kg} / \mathrm{m}^{3}$ in T1D4 to $4.01 \mathrm{~kg} / \mathrm{m}^{3}$ in T3D3; while for the wet season, WUE Irr ranged from $2.26 \mathrm{~kg} / \mathrm{m}^{3}$ in T1D4 to $4.83 \mathrm{~kg} / \mathrm{m}^{3}$ in T4D3. Similarly, for the three characteristic seasons, the minimum and maximum WUE $E_{\mathrm{ET}}$ were observed in the same combinations with ranges of $2.42-3.48 \mathrm{~kg} / \mathrm{m}^{3}$, $2.51-3.22 \mathrm{~kg} / \mathrm{m}^{3}$ and $2.48-3.32 \mathrm{~kg} / \mathrm{m}^{3}$ for the dry, normal and wet seasons, respectively (Table 1 ). The percent relative change in $\mathrm{WUE}_{\mathrm{ET}}$ for each strategy compared to the maximum WUE $\mathrm{ET}_{\mathrm{ET}}$ observed for the specific characteristic season is also presented in the table. The values on the lower end of this relative scale indicate that there is no substantial difference between the maximum WUE $E_{\mathrm{ET}}$ and the values observed in the respective strategy, implying that these strategies offer opportunities for improving water use. Specifically, utilizing a depletion schedule of 50\% (T3) and 60\% (T4) for initiating irrigation offers opportunities for water saving, as more than $50 \%$ of the values had a relative change of less than $5 \%$. Further, a depletion schedule of $40 \%$ (T2) can improve crop water productivity in irrigated maize production when using water application depths of 20 (D1) $\mathrm{mm}$ and 30 (D2) $\mathrm{mm}$; the relative change for these combinations compared to the maximum $\mathrm{WUE}_{\mathrm{ET}}$ is less than $9 \%$. Higher relative changes (lower WUE $\mathrm{ET}_{\mathrm{ET}}$ values) for the remaining combinations for this depletion schedule (T2D3 and T2D4) indicate that the increase in water application (Figure 2) did not result in an appreciable increase in grain yield.

Table 1. Crop water productivity estimated per unit irrigation water applied $\left(\mathrm{WUE}_{\mathrm{Irr}}, \mathrm{kg} / \mathrm{m}^{3}\right)$ and per unit seasonal evapotranspiration $\left(\mathrm{WUE}_{\mathrm{ET}}, \mathrm{kg} / \mathrm{m}^{3}\right)$ for the various depletion schedules and water application depths for the three characteristic seasons.

\begin{tabular}{ccccccccc}
\hline Productivity Variable & \multicolumn{9}{c}{ WUE $_{\text {Irr }}$} \\
\hline Depletion Levels & T1 & T2 & T3 & T4 & T1 & T2 & T3 & T4 \\
\hline Depths & \multicolumn{7}{c}{ WUE } \\
\hline D1 & 3.79 & 3.82 & 3.63 & 3.82 & $3.24(7)^{1}$ & $3.37(3)$ & $3.20(8)$ & $3.33(4)$ \\
D2 & 3.05 & 3.68 & 3.99 & 3.91 & $2.75(21)$ & $3.26(6)$ & 3.48 & $3.41(2)$ \\
D3 & 2.51 & 3.14 & 3.99 & 3.96 & $2.53(27)$ & $2.83(19)$ & 3.48 & $3.46(1)$ \\
D4 & 2.01 & 2.51 & 3.20 & 3.17 & $2.42(30)$ & $2.61(25)$ & $2.87(18)$ & $2.84(18)$ \\
\hline & \multicolumn{7}{c}{ Normal } \\
\hline D1 & 3.82 & 3.78 & 3.96 & 3.92 & $3.11(3)$ & $3.08(4)$ & $3.18(1)$ & $3.15(2)$ \\
D2 & 3.34 & 3.68 & 3.97 & 3.95 & $2.79(13)$ & $3.02(6)$ & $3.19(1)$ & $3.17(2)$ \\
D3 & 2.79 & 3.60 & 4.01 & 3.98 & $2.67(17)$ & $2.97(8)$ & 3.22 & $3.19(1)$ \\
D4 & 2.23 & 2.88 & 3.21 & 3.96 & $2.51(22)$ & $2.81(13)$ & $2.68(17)$ & $3.20(1)$ \\
\hline & \multicolumn{7}{c}{ Wet } \\
\hline D1 & 4.21 & 4.22 & 4.41 & 4.47 & $3.05(8)$ & $3.06(8)$ & $3.12(6)$ & $3.27(2)$ \\
D2 & 3.76 & 4.23 & 4.65 & 4.53 & $2.81(15)$ & $3.07(8)$ & $3.24(2)$ & $3.16(5)$ \\
D3 & 2.83 & 3.65 & 4.15 & 4.83 & $2.54(23)$ & $2.91(12)$ & $3.01(9)$ & 3.32 \\
D4 & 2.26 & 3.41 & 3.36 & 3.92 & $2.48(25)$ & $2.83(15)$ & $2.79(16)$ & $2.87(14)$ \\
\hline
\end{tabular}

Notes: ${ }^{1}$ Values in parenthesis represent percent relative change for each strategy compared to the maximum value in each characteristic season.

Estimated $W U E_{I r r}$ for the interval scheduling method is displayed in Table 2. As can be observed, the WUE $\mathrm{Irr}_{\mathrm{rr}}$ decreased with increasing water depths. Furthermore, considering the various combinations, in most cases, the variation in values between the three seasons was small. This can be 
attributed to the fact that the interval scheduling employed resulted in the same amount of irrigation water being supplied across the three seasons. For the three characteristic seasons, the highest values were observed in the Int10 schedule ranging from $2.18 \mathrm{~kg} / \mathrm{m}^{3}$ to $5.48 \mathrm{~kg} / \mathrm{m}^{3}$, which was expected given the lower amounts of irrigation water supplied. Across the three characteristic seasons, the mean relative reduction in $\mathrm{WUE}_{\text {Irr }}$ for the schedules Int5, Int7, Int7-5, Int10-5 and Int10-7 compared

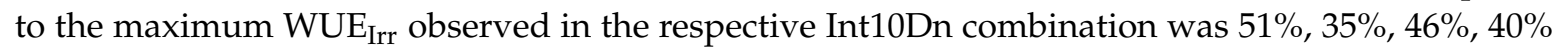
and $24 \%$, respectively. A greater disparity in $\mathrm{WUE}_{\mathrm{ET}}$ (Table 3) values between seasons was observed for the different simulations compared to the values in $W \mathrm{UE}_{\mathrm{Irr}}$ (Table 2). However, the difference was less pronounced at the higher water depths of D3 and D4. Again, higher WUE $E_{\mathrm{ET}}$ values were obtained for the Int10 schedule. For the dry characteristic season, the relative reduction in WUE $\mathrm{ET}_{\mathrm{ET}}$ for Int5, Int7, Int7-5, Int10-5 and Int10-7 compared to the maximum WUE $E_{\mathrm{ET}}$ observed in the respective Int10Dn combinations was within the range of $2-38 \%, 4-29 \%, 3-40 \%, 4-35 \%$ and $5-21 \%$, respectively. For the normal characteristic season, the relative reduction for the respective combinations was within the range of $5-31 \%, 4-26 \%, 1-31 \%, 4-29 \%$ and $3-18 \%$. Additionally, the relative reduction for the respective combinations for the wet characteristic season ranged from $2-25 \%, 2-26 \%, 3-37 \%, 4-23 \%$ and $4-13 \%$. In the dry, normal and wet season, 7,8 and 12 cases (out of 20), respectively, recorded less than or equal to $10 \%$ reduction in $\mathrm{WUE}_{\mathrm{ET}}$ compared to the maximum WUE $\mathrm{ET}_{\mathrm{ET}}$ simulated for the respective IntnDn combinations.

Comparison between the numerical outputs of yield and WUE $\mathrm{Irr}_{\mathrm{Ir}}$ and WUE $\mathrm{ET}$ generally informs about the suitability of irrigation strategies for improving agricultural water productivity [3]. For a characteristic dry/normal season, high yields and high $\mathrm{WUE}_{\mathrm{Irr}}$ and $\mathrm{WUE}_{\mathrm{ET}}$ observed for the following combinations indicate practical schedules for water savings without significant yield penalty: T2D1, T2D2, T3D1, T3D2 and T3D3. Considering a wet season, feasible schedules include T2D1, T2D2, T3D1, T3D2, T3D3, T4D2 and T4D3. Although a depletion of 50-55\% is typically recommend [24], the results indicate that a depletion schedule of $60 \%$ (T4) with large water application depths is viable for this location for priorities of improving agricultural water use. Of course, in water scarcity conditions, the lower water application depths should be used. The results also indicate that although utilizing a depletion schedule of $30 \%$ (T1) resulted in high yields, the lower WUE ${ }_{\text {Irr }}$ and WUE $E_{\mathrm{ET}}$ (except for a $20 \mathrm{~mm}$ (D1) depth (Table 1)) imply that the higher water application amounts (Figure 2) did not result in a substantial increase in productivity; thus, utilizing this schedule is not sustainable towards the goal of water saving. Further supporting this is the observation that the simulated yields for T1 were not significantly different from those simulated in T2 (Table S1). As regards the irrigation scheduling interval method, utilization of the schedule Int7-5 at water application depths of 40 (D3) and 50 (D4) $\mathrm{mm}$ for the dry and normal seasons and depths of 30 (D2) to 50 (D4) $\mathrm{mm}$ for the wet season can be used. In these cases, both the relative reduction in yield $(<1.5 \%)$ and WUE $\mathrm{WT}_{\mathrm{ET}}(<10 \%)$ compared to the maximum were among the lowest. The schedules Int10-5 and In10-7 at depths of 30 to $50 \mathrm{~mm}$ resulting in less than $4 \%$ reduction in yield and less than $12 \%$ change in WUE to the maximum for both the wet and normal years are also feasible strategies. On this relative basis, the schedule Int $10-5$ for depths of $40 \mathrm{~mm}$ and $50 \mathrm{~mm}$ can be utilized for a dry characteristic season. Considering however the simulated deep percolation, high water losses observed for higher water depths suggest that the lower depths in the aforementioned cases should be employed. Further, it should be noted that for these three aforementioned schedules, a water depth of $20 \mathrm{~mm}$ (D1) can also be used, especially considering that the lowest percolation losses (ranging from $0-21 \%$ across all three characteristic seasons and the various schedules) were obtained at this water depth, but a significantly higher yield penalty is to be expected. Highly significant differences $(p<0.01)$ were observed between $\mathrm{D} 1$ and depths D2 to D4 on yield (Table S2). Although the highest WUE $\mathrm{ET}_{\mathrm{ET}}$ and WUE $\mathrm{Err}_{\mathrm{Ir}}$ were observed for the Int10 schedule, a higher yield penalty would be a limiting factor to its practicality. However, as the lowest water losses to deep percolation were observed for this schedule, it can be a viable strategy especially for a projected wet characteristic season. Similarly, although the highest yields were generally observed in the Int5 schedule, low WUE $\mathrm{ET}_{\mathrm{ET}}$ suggests that the feasibility of this strategy 
for sustainable use of water resources is inadequate. Furthermore, high percolation losses associated with this schedule supports this. In using ISIAMod (Irrigation Scheduling Impact Assessment Model), Igbadun and Salim [11] and Igbadun et al. [25] also illustrated that using a five-day interval schedule does not benefit agricultural productivity in terms of yield and water productivity.

Table 2. Crop water productivity $\left(\mathrm{WUE}_{\mathrm{Irr}}, \mathrm{kg} / \mathrm{m}^{3}\right)$ for the various interval schedules and water application depths for the three characteristic seasons.

\begin{tabular}{cccccccc}
\hline \multirow{2}{*}{ Water Depths } & \multicolumn{7}{c}{ Interval Schedules } \\
\cline { 2 - 8 } & Int5 & Int7 & Int10 & Int7-5 & Int10-5 & Int10-7 & Int5 \\
\hline & & \multicolumn{7}{c}{ Dry } \\
\hline D1 & 2.66 & 3.52 & 5.28 & 2.92 & 3.19 & 3.98 & 2.66 \\
D2 & 1.78 & 2.36 & 3.61 & 1.96 & 2.19 & 2.73 & 1.78 \\
D3 & 1.34 & 1.78 & 2.73 & 1.47 & 1.65 & 2.05 & 1.34 \\
D4 & 1.07 & 1.42 & 2.18 & 1.18 & 1.32 & 1.64 & 1.07 \\
\hline & & & \multicolumn{7}{c}{ Normal } \\
D1 & 2.66 & 3.55 & 5.22 & 2.93 & 3.23 & 4.03 & 2.66 \\
D2 & 1.78 & 2.37 & 3.64 & 1.97 & 2.20 & 2.75 & 1.78 \\
D3 & 1.33 & 1.79 & 2.74 & 1.48 & 1.65 & 2.06 & 1.33 \\
D4 & 1.07 & 1.43 & 2.19 & 1.18 & 1.32 & 1.65 & 1.07 \\
\hline & & & \multicolumn{7}{c}{ Wet } \\
\hline D1 & 2.67 & 3.56 & 5.48 & 2.96 & 3.31 & 4.13 & 2.67 \\
D2 & 1.79 & 2.38 & 3.66 & 1.98 & 2.21 & 2.76 & 1.79 \\
D3 & 1.34 & 1.79 & 2.75 & 1.48 & 1.66 & 2.07 & 1.34 \\
D4 & 1.07 & 1.43 & 2.20 & 1.19 & 1.33 & 1.66 & 1.07 \\
\hline
\end{tabular}

Table 3. Crop water productivity $\left(\mathrm{WUE}_{\mathrm{ET}}, \mathrm{kg} / \mathrm{m}^{3}\right)$ for the various interval schedules and water application depths for the three characteristic seasons.

\begin{tabular}{cccccccc}
\hline \multirow{2}{*}{ Water Depths } & \multicolumn{7}{c}{ Interval Schedules } \\
\cline { 2 - 8 } & Int5 & Int7 & Int10 & Int7-5 & Int10-5 & Int10-7 & Int5 \\
\hline & & \multicolumn{7}{c}{ Dry } \\
\hline D1 & 2.73 & 3.13 & 4.42 & 2.65 & 2.86 & 3.47 & 2.73 \\
D2 & 2.64 & 2.51 & 3.20 & 2.60 & 2.56 & 2.49 & 2.64 \\
D3 & 2.57 & 2.52 & 2.86 & 2.54 & 2.56 & 2.47 & 2.57 \\
D4 & 2.51 & 2.46 & 2.56 & 2.47 & 2.47 & 2.42 & 2.51 \\
\hline & & \multicolumn{7}{c}{ Normal } \\
D1 & 2.72 & 2.93 & 3.93 & 2.70 & 2.79 & 3.24 & 2.72 \\
D2 & 2.60 & 2.63 & 2.99 & 2.65 & 2.57 & 2.70 & 2.60 \\
D3 & 2.64 & 2.51 & 2.82 & 2.58 & 2.55 & 2.62 & 2.64 \\
D4 & 2.48 & 2.51 & 2.60 & 2.58 & 2.50 & 2.53 & 2.48 \\
\hline & & \multicolumn{7}{c}{ Wet } \\
\hline D1 & 2.73 & 2.69 & 3.64 & 2.66 & 2.81 & 3.19 & 2.73 \\
D2 & 2.60 & 2.49 & 2.90 & 2.62 & 2.54 & 2.59 & 2.60 \\
D3 & 2.60 & 2.47 & 2.60 & 2.52 & 2.55 & 2.50 & 2.60 \\
D4 & 2.48 & 2.47 & 2.54 & 2.45 & 2.42 & 2.43 & 2.48 \\
\hline
\end{tabular}

\section{Conclusions}

Effective management of water for agricultural production requires the use of innovative and sustainable approaches. In this study, the AquaCrop water productivity model was used in combination with long series of climate data and frequency analysis to study the impact of different irrigation scheduling scenarios for a maize crop in a tropical environment under three characteristic 
seasons: dry, normal and wet. Two irrigation scheduling scenarios were considered: a depletion schedule, which focuses on initiating irrigation at a predefined allowable depletion of available soil water in the root zone, and interval scheduling, where irrigation is applied at fixed intervals. The study identified several irrigation strategies for the priorities of improving agricultural water use in irrigated maize production while stabilizing yields for surface irrigation farming. The information would be useful when making a recommendation on the appropriate irrigation scheduling protocols for optimal water management to farmers. Complementary studies exploring the economic dimension would be valuable.

Under a depletion scheduling method, for a characteristic dry and normal season, an irrigation schedule at $40 \%$ and $50 \%$ maximum allowable depletion of available soil water at water depths of 20-40 $\mathrm{mm}$ in loamy soils offers opportunities for farmers to improve field water use efficiency without significant yield penalty. Results indicate that for a wet characteristic season, a depletion schedule of $50 \%$ at lower water depths of 20-30 mm can be utilized for improved WUE, and depletion levels can even extend to a depletion level of $60 \%$ at $40-50 \mathrm{~mm}$.

Under an interval scheduling approach, simulated results indicated that irrigating the maize crop at fixed intervals of seven or 10 days leads to significant reduction in seasonal water applied and in the associated deep percolation losses, but at significantly $(p<0.05)$ higher yield penalty compared to a five-day interval. Utilizing a fixed daily schedule of five-day intervals procures high grain yield, but with higher irrigation demand and considerably high percolation losses, resulting in this schedule being unsustainable. Feasible strategies that resulted in a good balance between simulated yield, improved water use efficiency and considerable deep percolation reduction were the 7 day- 5 day schedule, the 10 day- 5 day schedule and the 10 day- 7 day schedule. For these schedules, water application depths of 30-50 $\mathrm{mm}$ can be used, with the higher depths being more applicable for a dry or normal characteristic season. The $30 \mathrm{~mm}$ water depth can be an effective water depth to be used for a characteristic wet season to minimize percolation losses.

\section{Some Remarks on Future Scope and Challenges}

Identifying irrigation strategies for the priorities of improving agricultural water use have a pivotal role to play in agricultural production growth, conservation of ecosystems and sustainable water development. However, sustainable management of water resources in irrigated agriculture, and by extension the findings in this study, will be greatly influenced by climate change and climate variability. Some of the most obvious impacts include: changes in annual and seasonal crop water requirements, changes in the availability of water and changes in water supply and demand owing to changes in the spatial and temporal distribution of rainfall. Changes in crop varieties, planting times and field management practices have been widely offered and acknowledged to be effective adaptation measures against future climate challenges. Thus, complementary studies in the future would be recommended.

The scope of the sustainable management of water resources in agriculture concerns the responsibility of water managers and users. Accordingly, another significant challenge will be linking simulation with adoption. Of course, the reliability of models and simulation results are important factors for identifying irrigation strategies for improving agricultural water productivity, but an important element of generating relevant and reliable information is synthesizing knowledge effectively and applying it appropriately. Adoption of the proposed strategies at regional scales or at the farm level will be greatly influenced by farmers' objectives, methodological limitations and financial constraints. Irrigation scheduling can be a complex decision making process, as it is dependent on several factors, including, but not limited to, knowledge of crop water requirements and yield responses to water, the constraints to and specifics of local farm management and agricultural practices and the limitations (financially and technically) of farmers to adopt and implement viable solutions. The two irrigation scheduling approaches evaluated in this study have their associated merits and limitations and will thus be applicable to different situations. The depletion scheduling will 
be applicable to situations where equipment is available to consistently monitor the soil water status and the farmer has the technical aptitude to work with the equipment and interpret the measurements. In contrast, the interval schedule has less financial obligations and technological demands, thus it will be applicable to situations where there are financial and technical constraints and where data are not timely and readily available. Different objectives by farmers, such as maximizing profits and or crop yields, can be important limitations to water management strategies for the benefits of improved water use efficiency in agriculture. Addressing knowledge and information deficiencies can reduce the gap between simulation studies and the adoption of beneficial results.

Supplementary Materials: The following are available online at www.mdpi.com/2071-1050/9/4/630/s1, Tables S1 and S2 showing the result of Tukey's significant test between the groups' effect on seasonal evapotranspiration and yield for the depletion scheduling method and interval scheduling method are available online.

Acknowledgments: Sincere gratitude is expressed to the Taiwan International Cooperation and Development Fund (ICDF) for their support in making this research possible. The authors wish to thank Mr. Andre Williams for critical reading of the manuscript. The authors gratefully acknowledge the financial support from the Ministry of Science and Technology (MOST), Taiwan under the grant of MOST 105-2221-E-020-009.

Author Contributions: Geneille Greaves and Yu-Min Wang conceived of and designed the study. Geneille Greaves conducted the simulations, analyzed the data and wrote the paper. Yu-Min Wang advised the work and critically reviewed the paper.

Conflicts of Interest: The authors declare no conflict of interest.

\section{References}

1. Findi, E. Introduction to Irrigation Principles; University of Duhok: Duhok, Kurdistan, 2012.

2. Leflaive, X.; Witmer, M.; Martin-Hurtado, R.; Bakker, M.; Kram, T.; Bouwman, L.; Visser, H.; Bouwman, A.; Hilderink, H.; Kim, K. Water. In OECD Environmental outlook to 2050: The Consequences of Inaction; OECD Publishing: Paris, France, 2012; p. 208.

3. Geerts, S.; Raes, D.; Garcia, M. Using AquaCrop to derive deficit irrigation schedules. Agric. Water Manag. 2010, 98, 213-216. [CrossRef]

4. Liu, J.; Wiberg, D.; Zehnder, A.J.B.; Yang, H. Modeling the role of irrigation in winter wheat yield, crop water productivity, and production in China. Irrig. Sci. 2007, 26, 21-33. [CrossRef]

5. Raes, D.; Steduto, P.; Hsiao, T.C.; Fereres, E. AquaCrop-The FAO crop model to simulate yield response to water: II. Main algorithms and software description. Agron. J. 2009, 101, 438-447. [CrossRef]

6. Steduto, P.; Hsiao, T.C.; Raes, D.; Fereres, E. AquaCrop-The FAO crop model to simulate yield response to water: I. concepts and underlying principles. Agron. J. 2009, 101, 426-437. [CrossRef]

7. Farahani, H.J.; Izzi, G.; Oweis, T.Y. Parameterization and evaluation of the AquaCrop model for full and deficit irrigated cotton. Agron. J. 2009, 101, 469-476. [CrossRef]

8. Abi Saab, M.T.; Todorovic, M.; Albrizio, R. Comparing AquaCrop and CropSyst models in simulating barley growth and yield under different water and nitrogen regimes: Does calibration year influence the performance of crop growth models? Agric. Water Manag. 2015, 147, 21-33. [CrossRef]

9. Todorovic, M.; Albrizio, R.; Zivotic, L.; Abi Saab, M.-T.; Stöckle, C.; Steduto, P. Assessment of AquaArop, CropSyst, and WOFOST models in the simulation of sunflower growth under different water regimes. Agron. J. 2009, 101, 509-521. [CrossRef]

10. Amiri, E.; Rezaei, M.; Rezaei, E.E.; Bannayan, M. Evaluation of Ceres-Rice, Aquacrop and Oryza2000 models in simulation of rice yield response to different irrigation and nitrogen management strategies. J. Plant Nutr. 2014, 37, 1749-1769. [CrossRef]

11. Levidow, L.; Zaccaria, D.; Maia, R.; Vivas, E.; Todorovic, M.; Scardigno, A. Improving water-efficient irrigation: Prospects and difficulties of innovative practices. Agric. Water Manag. 2014, 146, 84-94. [CrossRef]

12. Igbadun, H.E.; Mahoo, H.F.; Tarimo, A.K.P.R.; Salim, B.A. Irrigation scheduling scenarios studies for a maize crop in Tanzania using a computer-based simulation model. Agric. Eng. Int. CIGR Ejournal 2006, 8, 1-27.

13. English, M.; Solomon, K.; Hoffman, G. A paradigm shift in irrigation management. J. Irrig. Drain. Eng. 2002, 128, 267-277. [CrossRef] 
14. Igbadun, H.E.; Salim, B.A. Simulation study of yield and soil water balance responses of a maize crop to farmers' irrigation scheduling practices in Tanzania. Irrig. Drain. Syst. Eng. 2014, 3, 1-7. [CrossRef]

15. Tfwala, S.S.; Wang, Y.-M. Estimating sediment discharge using sediment rating curves and artificial neural networks in the Shiwen River, Taiwan. Water 2016, 8, 53. [CrossRef]

16. Sakthivadivel, R.; Aloysius, N.; Matsuno, Y. Assessment of Performance and Impact of Irrigation and Water Resources Systems in Taiwan and Sri Lanka; International Water Management Institute: Colombo, Sri Lanka, 2001.

17. Liou, Y.-A.; Liu, H.-L.; Chou, C.-H. Vanishing ponds and regional water resources in Taoyuan, Taiwan. Terr. Atmos. Ocean. Sci. 2015, 26, 161-168. [CrossRef]

18. Greaves, G.; Wang, Y.-M. Assessment of FAO AquaCrop Model for Simulating Maize Growth and Productivity under Deficit Irrigation in a Tropical Environment. Water 2016, 8, 557. [CrossRef]

19. Raes, D.; Steduto, P.; Hsiao, T.C.; Fereres, E. AquaCrop Reference Manual, version 4; FAO_Land and Water Division: Rome, Italy, 2012.

20. Geerts, S.; Raes, D.; Garcia, M.; Taboada, C.; Miranda, R.; Cusicanqui, J.; Mhizha, T.; Vacher, J. Modeling the potential for closing quinoa yield gaps under varying water availability in the Bolivian Altiplano. Agric. Water Manag. 2009, 96, 1652-1658. [CrossRef]

21. Cancela, J.J.; Cuesta, T.S.; Neira, X.X.; Pereira, L.S. Modelling for improved irrigation water management in a temperate region of northern Spain. Biosyst. Eng. 2006, 94, 151-163. [CrossRef]

22. Liu, Y.; Li, Y.N.; Pereira, L.S.; Fernando, R.M.; Teixeira, J.L. Irrigation management strategies for water saving in North China plain. In The XIV Memorial CIGR World Congress (CD-ROM paper R 1105); CIGR: Tsukuba, Japan, 2000.

23. Raes, D.; Willems, P.; Gbaguidi, F. RAINBOW-A software package for analyzing data and testing the homogeneity of historical data sets. In Proceedings of the 4th International Workshop on "Sustainable management of marginal drylands (SUMAMAD)", Islamabad, Pakistan, 27-31 January 20061.

24. Allen, R.G.; Pereira, L.S.; Raes, D.; Smith, M. Crop Evapotranspiration: Guidelines for Computing Crop Requirements; FAO—Food and Agriculture Organization of the United Nations: Rome, Italy, 1998; pp. 1-15.

25. Jamieson, P.D.; Martin, R.J.; Francis, G.S.; Wilson, D.R. Drought effects on biomass production and radiation-use efficiency in barley. F. Crop. Res. 1995, 43, 77-86. [CrossRef]

26. Farré, I.; Faci, J.M. Comparative response of maize (Zea mays L.) and sorghum (Sorghum bicolor L. Moench) to deficit irrigation in a Mediterranean environment. Agric. Water Manag. 2006, 83, 135-143. [CrossRef]

27. Çakir, R. Effect of water stress at different development stages on vegetative and reproductive growth of corn. Field Crops Res. 2004, 89, 1-16. [CrossRef]

28. Djaman, K.; Irmak, S.; Rathje, W.R.; Martin, D.L.; Eisenhauer, D.E. Maize evapotranspiration, yield production functions, biomass, grain yield, harvest index, and yield response factors under full and limited irrigation. Am. Soc. Agric. Biol. Eng. 2013, 56, 273-293.

(C) 2017 by the authors. Licensee MDPI, Basel, Switzerland. This article is an open access article distributed under the terms and conditions of the Creative Commons Attribution (CC BY) license (http:/ / creativecommons.org/licenses/by/4.0/). 